\title{
Selective excitotoxic lesions of the nucleus accumbens core and shell differentially affect aversive Pavlovian conditioning to discrete and contextual cues
}

\author{
J. A. PARKINSON, T. W. ROBBINS, and B. J. EVERITT \\ University of Cambridge, Cambridge, England
}

\begin{abstract}
The nucleus accumbens (NAcc) is implicated in reward-related processes and in reinforcement learning. However, its precise role in associative processes is unclear and may not be related solely to appetitive learning. In the present study, the differential effects of selective excitotoxic lesions of the NAcc core and shell were studied on the acquisition of an aversive Pavlovian conditioning task that assessed conditioning to both discrete and contextual cues. Rats with selective lesions of the NAcc shell were not impaired on measures of aversive Pavlovian conditioning to either discrete or contextual cues. In contrast, animals with lesions of the NAcc core showed an impairment in conditioning to discrete cues and an enhancement in conditioning to contextual cues. The NAcc is thus implicated in aspects of aversive Pavlovian conditioning; the significance of this finding for theories of cortico-striatal function is discussed.
\end{abstract}

The nucleus accumbens (NAcc) has been strongly implicated in reward-related processes (Balleine \& Killcross, 1994; Cador, Robbins, \& Everitt, 1989; Everitt, Morris, O'Brien, \& Robbins, 1991). In particular, it has been suggested that the mesolimbic dopamine (DA) system that innervates the NAcc mediates the reinforcing effects of a variety of stimuli, including food, sex, and drugs of abuse, as well as the subjective hedonic effects of these rewards (Di Chiara, 1998; Wise \& Bozarth, 1987).

It has also been suggested that the NAcc, together with its DAergic innervation, may be more generally involved in both appetitive and aversive motivational processes (see Salamone, 1994, for review). For example, increased levels of extracellular DA in the NAcc (as measured by in vivo microdialysis) have been observed during the presentation of aversive stimuli such as footshock (Kalivas \& Duffy, 1997; Thierry, Tassin, Blanc, \& Glowinski, 1976) and restraint stress (Imperato, Angelucci, Casolini, Zocchi, \& Puglisiallegra, 1992) and also in response to conditioned stimuli that are predictive of footshock (Wilkinson et al., 1998; Young, Ahier, Upton, Joseph, \& Gray, 1998; Young, Joseph, \& Gray, 1993). Wilkinson et al. observed increases in DA within the NAcc that were closely corre-

J.A.P. was in receipt of a BBSRC research fellowship and the Oon Khye Beng Ch'hia Tsio Scholarship, awarded by Downing College, Cambridge. This work was supported by a Wellcome Trust Programme Grant (T.W.R., B.J.E., A. Roberts, and B. J. Sahakian). The authors thank Caroline Morrison and Helen Sweet for their assistance with the histological assessment for this study. Correspondence should be addressed to J. A. Parkinson, Department of Experimental Psychology, University of Cambridge, Downing Street, Cambridge CB2 3EB, England (e-mail: jap22@cam.ac.uk). lated with the conditioned behavioral response of freezing during learning and extinction, while increases in DA within the medial prefrontal cortex occurred on the initial conditioning trials and were suggested to be related more to the processing of novel aspects of the stimuli. However, significantly smaller neuronal responses to aversive events relative to appetitive events have also been observed (Mirenowicz \& Schultz, 1996) and even decreases in extracellular DA, within the NAcc, in response to aversively conditioned tastes (Mark, Blander, \& Hoebel, 1991).

Manipulations of the striatum also produce effects on aversive learning. For example, Riedel and colleagues (Riedel, Harrington, Hall, \& MacPhail, 1997) found that electrolytic lesions restricted to the NAcc shell impaired aversive conditioning to contextual cues while leaving conditioning to distinct stimuli unaffected. Further, animals with 6-hydroxydopamine (6-OHDA) lesions of the NAcc were impaired on a test of active avoidance requiring leverpresses to avoid footshock (McCullough, Sokolowski, \& Salamone, 1993) and also on a test of passive avoidance (Schwarting \& Carey, 1985).

The effects of NAcc manipulations may be the result of altering information processing through discrete limbic cortico-ventral striatal loops (Alexander, Delong, \& Strick, 1986; Pennartz, Dasilva, \& Groenewegen, 1994). Thus, lesions of the anterior cingulate cortex in animals have been shown to attenuate fear conditioning (Buchanan \& Powell, 1982; Powell, Watson, \& Maxwell, 1994), while damage to the anterior cingulate cortex in humans has been reported to produce apathy, depression, and indifference to pain (see Devinsky, Morrell, \& Vogt, 1995). There is also evidence supporting an important role for the amygdala (Killcross, Robbins, \& Everitt, 1997a; Phillips 
\& LeDoux, 1992; Sananes \& Davis, 1992; Selden, Everitt, Jarrard, \& Robbins, 1991; and see LeDoux, Cicchetti, Xagoraris, \& Romanski, 1990; Maren \& Fanselow, 1996) and hippocampus (Kim \& Fanselow, 1992; Phillips \& LeDoux, 1992; Selden et al., 1991) in fear conditioning, both structures projecting to the NAcc (Zahm \& Brog, 1992). For example, Selden et al. (1991) studied the effects of excitotoxic lesions to either the amygdala or the hippocampus on an aversive Pavlovian conditioning task. Animals with lesions of the amygdala showed a selective impairment in conditioning to a discrete conditioned stimulus (CS; contextual conditioning was unimpaired), while animals with lesions of the hippocampus showed a selective impairment in conditioning to the context (CS conditioning was unimpaired)-a double dissociation of these effects on CS and contextual conditioning.

The present study therefore investigated the effects of pretraining lesions selectively to the NAcc core and shell subregions on aversive Pavlovian conditioning to both discrete and contextual stimuli. Because projections from the amygdala and hippocampus converge topographically across the NAcc (Wright, Beijer, \& Groenewegen, 1996; Zahm \& Brog, 1992), separate subregions of the NAcc may mediate distinct aspects of CS and contextual conditioning.

The procedure was similar to that used by Selden et al. (1991). The CS was a 30-sec auditory clicker, while the unconditioned stimulus (US) was a 0.5 -sec, $0.5-\mathrm{mA}$ footshock. Animals were water deprived and given five $\mathrm{CS} \rightarrow$ US pairings in a distinct environment (context) with either a 10-sec (short trace) or 30-sec (long trace) interval between the termination of the CS and the onset of the US. Later, animals were given two tests: First, they were placed into a separate chamber and presented with the aversive CS, and aversive conditioning was assessed by quantifying its suppressive effect on drinking water (conditioned lick suppression). Second, animals were placed again into the chamber in which they had previously received footshock, but were allowed to move between that chamber and a second, neutral chamber in a conditioned place aversion test. The extent to which animals had conditioned to the context was measured by their avoidance of the chamber in which they had been shocked.

In the study by Selden et al. (1991), sham control animals in the short trace group conditioned to the CS and not to the context, while those in the long trace group conditioned to the context and not to the CS (Marlin, 1981). According to learning theory (see Dickinson, 1980), distinct stimuli and configurations of contextual stimuli compete for associative strength during learning, and one of the critical elements in this form of Pavlovian associative learning is the temporal contingency between CS and US. Consequently, animals will learn which type of stimuli (CS or context) best predicts the aversive shock. With a short interval between CS and US, animals are more likely to associate the discrete CS with the US. However, when there is a trace interval between the CS and US, leading to a temporal contiguity between these stim- uli, animals are more likely to associate the competing cues that make up the context with the US (Dweck \& Wagner, 1970; Marlin, 1981; Rescorla, 1968).

\section{METHOD}

The subjects were 74 male hooded Lister rats (Olac, Bicester, U.K.) weighing between 279 and $307 \mathrm{~g}$ at the time of surgery. The animals were housed in pairs in a colony room maintained at $21^{\circ} \mathrm{C}$ on a reverse 12:12-h light:dark cycle (lights off at $1000 \mathrm{~h}$ ) and were tested during the dark phase. Subjects had free access to food (laboratory chow, Purina) at all times, but access to water was limited to $60 \mathrm{~min}$ per day at $1800 \mathrm{~h}$ in the home cage for 4 days prior to and during the experiment. All animals used in these studies were treated in accordance with the U.K. 1986 Animals (Scientific Procedures) Act (Project License PPL 80/00668).

\section{Surgical Procedure}

Sham control groups were treated identically to the rats in lesion groups except that they received infusions of sterile phosphatebuffer (sterile PB) vehicle alone. Surgery was performed under Avertin anaesthesia (2,2,2-tribromoethanol, 2-Methylbutan-2-ol, Dulbecco "A" PBS tablets, and $\mathrm{ddH}_{2} 0$ in tertiary amyl alcohol [Sigma, U.K.]; $10 \mathrm{ml} / \mathrm{kg}$ body weight) using a stereotaxic frame (David Kopf, Tujunga, CA) fitted with atraumatic earbars, with the incisor bar set at $3.3 \mathrm{~mm}$ below the interaural line. A midline incision was made along the skull, then skin and fascia were cleared to reveal the bregma. A dental drill was used to remove bone above the injection sites before an appropriate infusion of neurotoxin was made stereotaxically. Infusions were made through a single burr hole using a $1-\mu \mathrm{l} \mathrm{SGE} \mathrm{(SGE,} \mathrm{Baton} \mathrm{Rouge,} \mathrm{LA)} \mathrm{syringe} \mathrm{(26} \mathrm{gauge:}$ Code 1BR-OC-7/0.47) with a custom-made glass micropipette attached to the end. Initially, pipettes (Intracel, U.K.) measured $1.2 \mathrm{~mm}$ external diameter, $0.69 \mathrm{~mm}$ internal diameter $\times 10 \mathrm{~cm}$ in length and were pulled using a Stoelting App-1 All Purpose Puller Model 52500, giving a final tip diameter of $50-100 \mathrm{~mm}$ and a length of $12 \mathrm{~mm}$.

Micropipettes were attached to the syringe using Araldite epoxy resin (Ciba, U.K.) to ensure an airtight seal. Core lesions were produced using $0.09 \mathrm{M}$ quinolinic acid (Sigma, U.K.), injected at the following coordinates: $\mathrm{AP}+1.2, \mathrm{~L} \pm 1.8$, skull surface -7.1 . Each injection was $0.5 \mu \mathrm{l}$, the micropipette being left in place for $2 \mathrm{~min}$ following injections. Shell lesions were produced using $0.06 \mathrm{M}$ ibotenic acid (Research Biochemicals, U.K.) using the following coordinates: AP $+1.6, \mathrm{~L} \pm 1.1$, skull surface $-6.4,-6.9,-7.9$. At the two most dorsal sites, a volume of $0.1 \mu \mathrm{l}$ ibotenic acid was injected, while $0.2 \mu \mathrm{l}$ was injected at the ventral site. Both quinolinic and ibotenic acid were infused in a solution adjusted to a $\mathrm{pH}$ of 7-7.4. The micropipette was left in place for $2 \mathrm{~min}$ following each infusion.

\section{Behavioral Procedure}

By altering the trace delay between an auditory stimulus and mild footshock, it is possible to selectively condition animals to either the discrete stimulus (with a close temporal contiguity) or the experimental context (using a long temporal delay between CS and shock) in which conditioning took place. Animals are not required to make any response during learning, and it is generally accepted that conditioning is Pavlovian in nature.

\section{Apparatus}

The two main pieces of equipment used were an operant lick chamber and a place preference/aversion apparatus. The operant lick chamber $(25 \times 22 \times 21 \mathrm{~cm})$ consisted of a steel plate floor and Plexiglas walls; two opposing walls were black, one white, and the 
fourth a clear wall that also served as a door. A 2.5 -W houselight was positioned in the center of the ceiling and remained lit throughout testing. A water spout was positioned in the center of one of the black walls and recorded drinking through the use of an integrated lickometer system operated by running a small electrical current through the lick tube and floor of the chamber. When animals made a licking response, a circuit was closed and the lickometer registered one lick. On the outside of the opposite wall, a heavy-duty relay was used to present the clicker CS+. The chamber was entirely encased within a sound-attenuating box, and a loudspeaker was positioned on the inside of this box in order to present a control nonconditioned stimulus.

Contextual learning was measured in a place preference apparatus. Two chambers, one with black walls and ceiling and the other white (each $25 \times 35 \times 39 \mathrm{~cm}$ ), were separated by a small central chamber $(12 \times 14 \times 39 \mathrm{~cm})$. In each of the large chambers, two sets of photocell beams, parallel with the end of the apparatus, were positioned $1 \mathrm{~cm}$ above the floor in order to measure both location and activity of the subject. The floor was a shock grid with bars $1 \mathrm{~cm}$ apart and $3 \mathrm{~cm}$ above a sawdust tray. The tray was black in the dark compartment and silver in the light compartment, though each was covered with fresh sawdust between trials. The two larger compartments could be divided by two Plexiglas panels (of the corresponding color), which allowed subjects to be restricted to the black side for conditioning or the central compartment prior to a place preference test. A heavy-duty relay, identical to the one in the operant lick chamber, was positioned on the outside of the central compartment to provide a clicker $\mathrm{CS}+$, and similarly a loudspeaker was positioned outside the central compartment to provide a control CS - stimulus. The CS+ was obtained by switching the relays on and off at a frequency of $4 \mathrm{~Hz}(60 \mathrm{~dB})$. This CS was chosen to minimize stimulus generalization, which might result from differences in the quality of sound generated in the separate apparatus used. The US was a $0.45-\mathrm{mA}$ scrambled footshock (Campden 521C) delivered through the grid floor of the place preference apparatus over a $0.5-\mathrm{sec}$ period.

\section{Procedure}

Subjects were well handled before and during the experiment. The deprivation schedule involved restricted access to water and consisted of $30 \mathrm{~min}$ free access to fresh water at $1800 \mathrm{~h}$ in the home cage. Deprivation lasted from 4 days prior to the behavioral testing to the termination of the experiment. Water consumption in the home cage was measured throughout the experiment. Subjects were allowed 7 days recovery following surgery before the experimental procedure was initiated.

Days 1 to 4. Each subject was placed in the operant lick chamber for $10 \mathrm{~min}$ and allowed free access to water via the lickometer system. The total number of licks, latency to start licking, and consumption of water were measured.

Day 5. Subjects received a $20-\mathrm{min}$ initial exposure to the place preference apparatus. Each animal was first placed into the central chamber and then both black and white panels were removed to allow the subject free access to explore both sides of the apparatus. The following measures were taken: latency to enter each side, activity in each compartment (as measured by photocell beams), and time spent in each compartment.

Day 6. Subjects were restricted to the black side of the place preference apparatus and received five clicker-footshock pairings, one pairing every $4 \mathrm{~min}$, and also four tone-no shock pairings $(60 \mathrm{~dB})$ over a 7 -min period (in order to later measure any generalized conditioning or response to this stimulus). The stimuli were of $30 \mathrm{sec}$ duration, and the shock parameters were $0.45 \mathrm{~mA}$ for $0.5 \mathrm{sec}$. Half the subjects in both the sham and lesion groups had a trace delay between the offset of the stimuli and the onset of the shock of $5 \mathrm{sec}$ (the short trace group). The other half of the subjects had a trace delay between offset of stimuli and onset of shock of $30 \mathrm{sec}$ (the long trace group). The order of clicker and tone was counterbalanced across subjects. Following conditioning, the black panel restricting subjects to the black side was removed, allowing access to the entire place preference apparatus. Subjects were given $6 \mathrm{~min}$ access to the apparatus in order to prevent generalized freezing behavior at test, as recommended by Odling-Smee (1975a, 1975b, 1978). Throughout the session, general activity measures were taken, and also time spent in each compartment.

Day 7. Animals were tested for conditioning to the discrete auditory stimulus in extinction. Each animal was given a 10 -min session in the operant lick chamber. The $30-\mathrm{sec}$ CS was triggered on the 30th lick, and lick suppression was calculated as the latency to complete 10 pre-CS licks divided by the latency to complete the 10 pre-CS licks plus the latency to complete 10 post-CS licks:

$$
\mathrm{SR}=(\text { latency } 20 \mathrm{th}-30 \text { th lick }) /(20 \mathrm{th}-40 \text { th lick }) \text {, }
$$

where the CS was presented on the 30th lick. Complete suppression to the CS would produce an SR tending toward 0 , while no suppression would produce an SR of 0.5.

Day 8. The extent to which subjects had conditioned to the context was tested. Each animal was placed in the central chamber of the place preference apparatus and then allowed free access to explore all compartments when the two restricting panels were removed simultaneously. Subjects were monitored for $20 \mathrm{~min}$ and the same measures were taken as those on Day 5 . The percentage change in the time spent outside of the black (conditioning) compartment before and after conditioning was calculated as a measure of aversive conditioning to the black chamber. This was calculated as the amount of time spent outside the black compartment during the habituation session (Day 5) divided by the amount of time spent outside the black compartment during the test session (Day 8) and then multiplied by 100 (to get a percentage figure).

Day 9. Generalized conditioning to the CS - was measured by assessing the response to the nonconditioned tone. Animals were placed in the operant lick chamber for $10 \mathrm{~min}$ and the 30th lick triggered the 30 -sec tone stimulus. The same measures were taken as those on Day 7.

\section{Statistical Analysis}

Since the studies were run separately and at different times, the analysis of core lesions and their sham controls was carried out independently of the analysis of shell lesions and their sham controls. Statistical analyses were performed using SPSS for Windows release 6.1.3 (SPSS Inc., Chicago) with further post hoc analyses being carried out using CLR ANOVA Version 2.0 for Macintosh (Clear Lake Research, Houston). Between-subjects analyses were conducted for lesion (core and core sham and shell and shell sham) and trace (short and long); within-subjects analyses were conducted for session (during habituation).

\section{RESULTS}

\section{Histological Assessment}

Figures 1 and 2 show schematic representations of lesions of the NAcc core and shell. Neuronal loss following NAcc core lesions extended rostrally from between +2.7 and $+2.5 \mathrm{~mm}$ from Bregma to $+0.5 \mathrm{~mm}$ caudally, along the anterior-posterior axis. Generally, the lesion did not extend into the rostral pole of the NAcc, nor was there damage to the ventral pallidum or olfactory tubercle. Following NAcc shell lesions, there was neuronal damage 

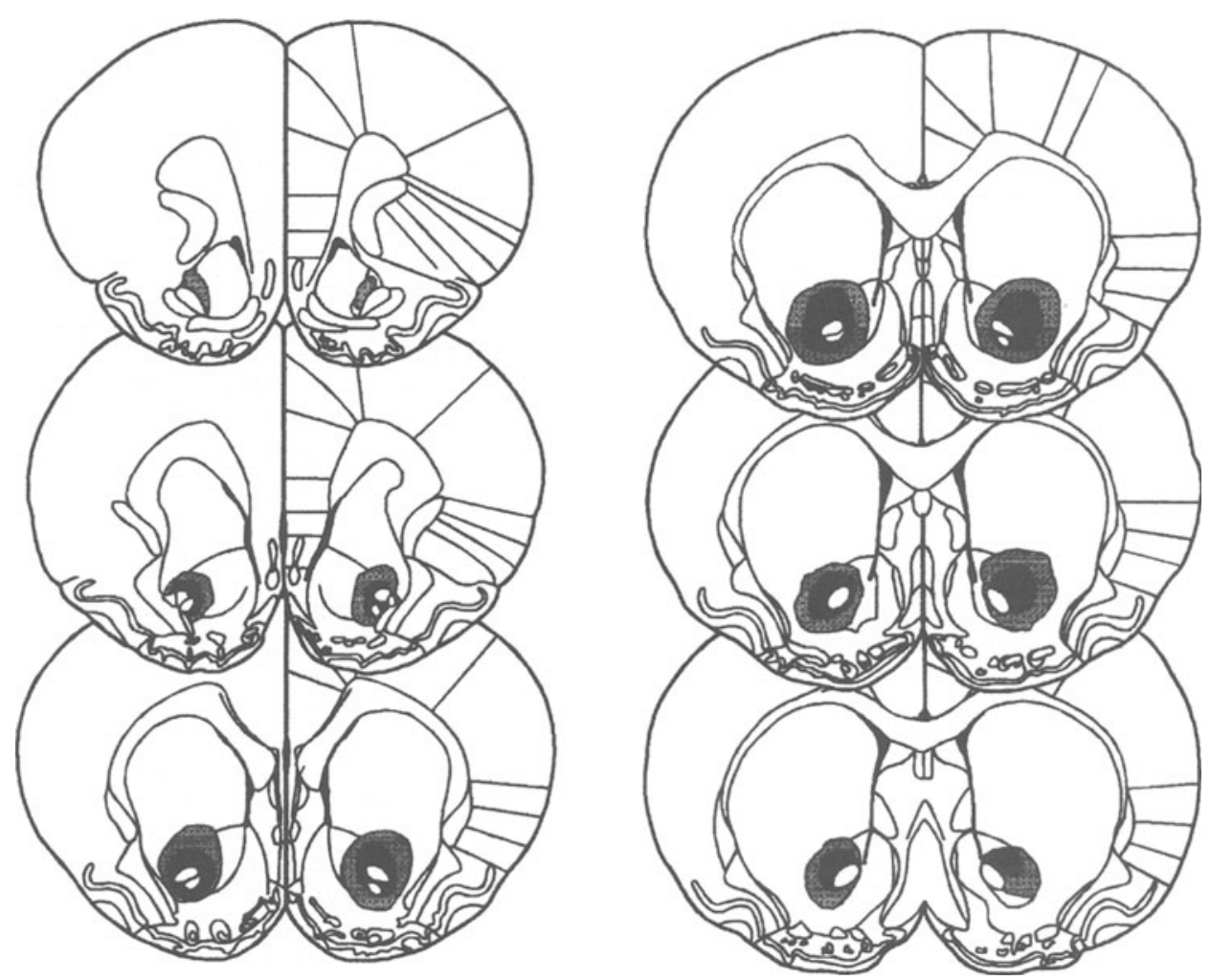

Figure 1. Schematic representation of lesions of the nucleus accumbens core, taken from Paxinos and Watson (1998). Sections are +2.7 to $+0.48 \mathrm{~mm}$ from bregma (AP) and show the smallest (black) and largest (gray) extent of the lesion.

typically ranging from +1.7 to $+0.48 \mathrm{~mm}$ from Bregma along the anterior-posterior axis, and from the base of the lateral ventricle dorsally, to the ventral portions of the medial shell, occasionally reaching the region of the olfactory tubercle. There was, in some cases, unilateral damage to the lateral septum or to the medial NAcc core.

Six animals in the shell group had lesions that were not restricted to the shell subregion of the NAcc (i.e., extending in to the core, septum, or the nucleus of the vertical limb of the diagonal band of Broca-VDB), and the data from these animals were removed from further analysis. Similarly, 3 animals in the core group had lesions extending beyond the core subregion (dorsally); the data from these animals were also removed. Thus final group numbers were (core, 15; core sham, 22; shell, 16; shell sham, 16).

\section{Behavioral Results}

\section{Effects of Nucleus Accumbens Core Lesions}

Preexposure to the lick operant chamber. During habituation to the LOC, the following measures were taken: the number of licks made during each 10-min session, the amount of water consumed, and the latency to the fifth lick. Analysis of the number of licks per 10-min session over the 4 habituation days revealed a lesion $\times$ session interaction $[F(3,78)=3, p<.05]$ that was characterized (using Newman-Keuls post hoc test) by a higher number of licks by the core lesioned animals on the first three sessions $(p<.05)$, but no significant difference by the final habituation session (sham averages for the four sessions were $592,622,567$, and 776 ; core averages were $864,773,732$, and 657$)$. There were no other significant effects [lesion: $F(1,26)=2.59, p=.12$ ]

Finally, analysis of the latency to commence licking also revealed no effects of lesion $[F(1,26)=0.08, p>.05]$ but did reveal a main effect of session $[F(3,78)=5.24, p<$ $.005]$, which reflected a general reduction in the latency over the four sessions (sham averages in seconds, 32, 30, 9, 4; core averages, $46,7,8.5,5.9$ ).

Preexposure to the place preference chamber. During a 20 -min habituation session, the amount of time spent in the "safe area" or nonshocked side (i.e., the middle passage and the white chamber) was recorded as well as the general level of activity as measured by photocell beams. Analysis of the time spent in the nonshocked side (sham average, $504 \mathrm{sec}$; core average, 512) revealed no significant difference between the core and sham lesioned animals $[F(1,35)=0.06, p>.05]$. Similarly, there 

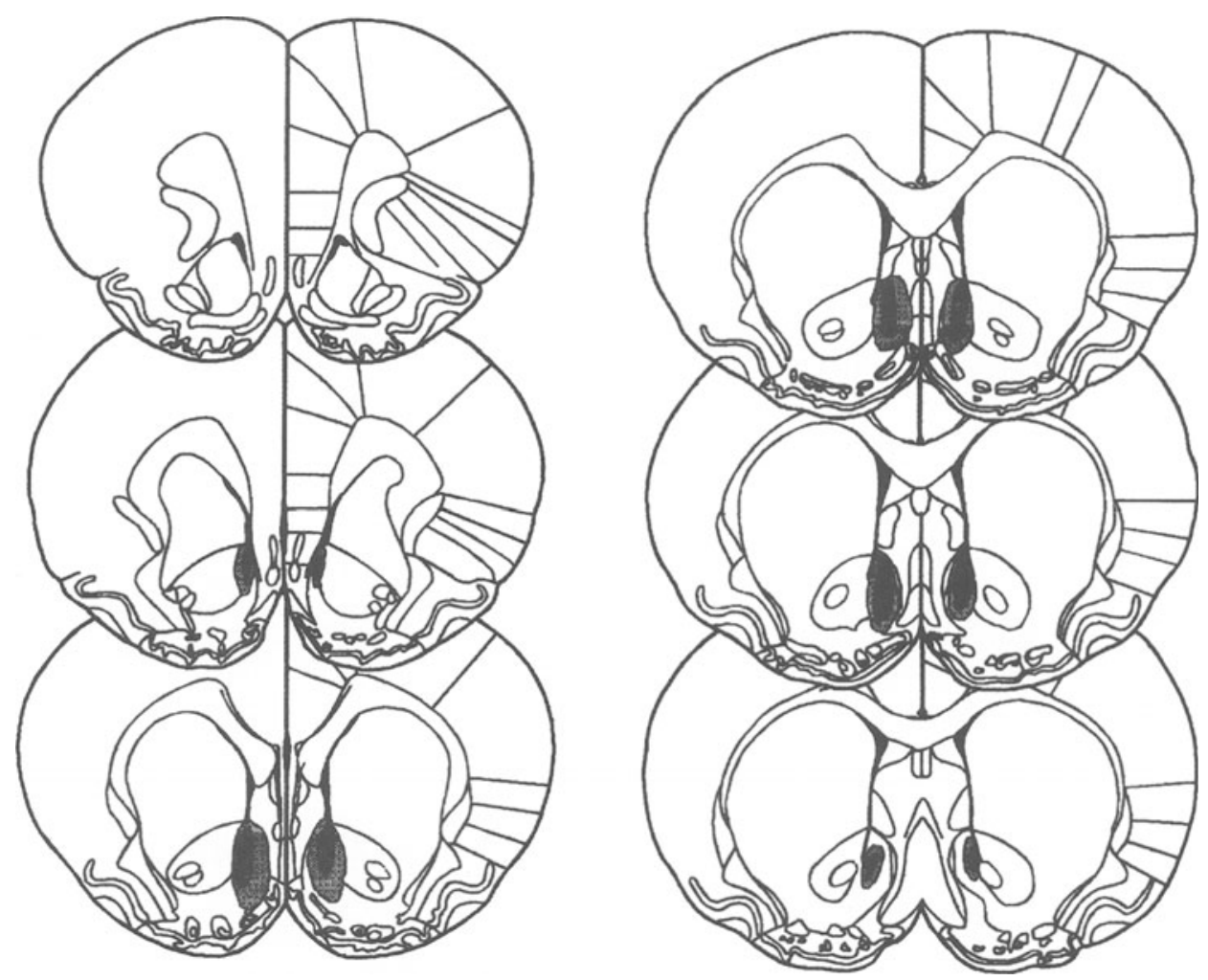

Figure 2. Schematic representation of lesions of the nucleus accumbens shell, taken from Paxinos and Watson (1998). Sections are +2.7 to $+\mathbf{0 . 4 8} \mathrm{mm}$ from bregma (AP) and show the smallest (black) and largest (gray) extent of the lesion.

was no significant difference in activity levels (sham average measured by beam breaks, 459 ; core average, 496 ) between the two groups $[F(1,35)=2.58, p=.13]$.

Conditioning to the discrete stimulus (CS+) and control (CS-). The analysis of lick suppression to the $C S+$ revealed a main effect of lesion $[F(1,36)=5.344, p<$ $.05]$, characterized by less suppression in the core group (the larger the SR value, the less the suppression) as well as a main effect of trace $[F(1,36)=11.66, p<.005]$, revealed as less suppression in the long trace (30-sec trace between CS and US) group, but also a lesion $\times$ trace interaction $[F(1,36)=4.57, p<.05]$. Post hoc analyses showed that while there was a significant difference between the sham short and sham long trace suppression ratios, characterized by a greater level of suppression in the sham short trace group $(p<.005)$, there was no such difference in the core lesioned animals (Figure $3 \mathrm{~A}$ ). Thus, there was significantly less suppression in the core short trace group relative to the sham short trace group $(p<.001)$.

There were no significant effects of the presentation of the CS+ on the total number of licks [lesion: $F(1,36)=$ $0.26, p>.05$; sham short trace, 414 ; sham long trace, 576 ; core short trace, 363 ; core long trace, 786$]$. There were also no significant effects of the lesion or trace interval on the latency to commence licking during the session [lesion: $F(1,36)=0.18, p>.05$; sham short trace, 9.2; sham long trace, 3.2; core short trace, 9; core long trace, 8]. Finally, there were no significant effects of the lesion or the trace on any measure (suppression, licks, or latency) during the presentation of the CS - (all analyses $F<2$, $p>.05$ ).

Conditioning to the context. The analysis of the percentage change in time spent in the nonshocked side (i.e., taking into account the effects of conditioning) revealed a lesion $\times$ trace interaction $[F(1,36)=4.23, p<$ .05]. Newman-Keuls post hoc analysis of the interaction demonstrated that the shams showed a significant effect of trace on the change in times spent in the nonshocked side $(p<.05)$, while trace had no effect in the core lesioned group (Figure 3B). Furthermore, there was a significant difference between the values for the core and sham lesioned short trace groups $(p<.05)$, but no significant difference between the long trace groups. Thus animals in the sham long trace group spent significantly more time in the nonshocked side than animals in the sham short trace group. There was no significant difference between the core lesioned short and long trace groups, revealing an increased level of contextual conditioning in the short trace core group.

There was no significant effect of the lesion on activity within the place preference chamber (PPC) [lesion: $F(1,36)=1.12, p>.05$; sham short trace, 333; sham long trace, 335; core short trace, 350; core long trace, 421]. 
Effects of Nucleus Accumbens Shell Lesions

Preexposure to the lick operant chamber. In relation to the number of licks over the four habituation sessions (sham average, 384, 258, 272, 214; shell average, 446, $364,325,288)$, there were no significant effects of lesion $[F(1,26)=1.65, p>.05]$, but there was a significant effect of session $[F(3,78)=11.38, p<.001]$, revealed as a reduction in the number of licks during Session 4 relative to Session $1(p<.05)$.

There was a main effect of session $[F(3,78)=24.3, p<$ $.001]$ for the latency to the fifth lick, characterized by a general reduction in latencies over sessions (sham average in seconds, $61,30,19,15$; shell average, $50,20,8.9,9.8)$. There were no effects of lesion $[F(1,26)=2.54, p=.12]$.

Preexposure to the place preference chamber. There was no significant difference between the shell and sham lesioned groups in relation to their habituation to the PPC: time in the nonshocked side $[F(1,26)=2.59, p=$ .12 ; sham average in seconds, 484; shell average, 530], activity $[F(1,26)=3.7, p=.07$; sham average measured by beam breaks, 443 ; shell average, 487$]$.

In summary, other than an initially high level of licking by the core lesioned animals (which declined to sham levels by the end of habituation), there were no significant effects of either the core or the shell lesion on the preexposure measures to the $\mathrm{LOC}$ or the $\mathrm{PPC}$ relative to their sham controls.

Conditioning to the discrete stimulus (CS+) and control (CS-). The shell lesion had no effect on lick suppression during the presentation of the CS+ [lesion: $F(1,27)=1.1, p>.05]$, though there was a main effect of trace $[F(1,27)=7.39, p<.05]$, characterized by a greater level of suppression by animals in the short trace groups (Figure 3C).

There were no other significant effects of any variable on responses to the CS+: total number of licks $\times$ lesion $[F(1,27)=0.165, p>.05$; sham short trace, 170 ; sham long trace, 246; shell short trace, 217; shell long trace, $274]$; latency to commence licking $\times$ lesion $[F(1,27)=$ $2.82, p>.05$; sham short trace, 51 ; sham long trace, 24; shell short trace, 31 ; shell long trace, 15].

Just as with lesions of the core, there were no significant effects of the shell lesion or the trace interval on any measure (suppression, licks, or latency) during the presentation of the CS - (all analyses, $F<2, p>.05$ ).

In summary, while short trace sham controls showed a significant level of suppression selectively to the presentation of the CS + , long trace sham controls did not suppress to the discrete auditory CS+. Animals with lesions of the NAcc shell showed a similar pattern of results. In contrast, animals with lesions of the NAcc core were impaired in CS conditioning since the short trace group did not show a significant level of suppression to the CS+ relative to sham performance and to the long trace group.

Conditioning to the context. Analysis of the percentage change in time spent in the nonshocked side, from pre- to postconditioning, revealed a significant main effect of trace $[F(1,26)=4.05, p<.05]$, again characterized by an increase in the time spent in the nonshocked side by the long trace groups relative to the short trace groups (Figure 3D). There was no effect of lesion $[F(1,26)=$ $0.06, p>.05]$.

There was no effect of lesion $[F(1,26)=1.85, p>$ $.05]$, but there was an almost significant effect of trace $[F(1,26)=4.23, p=.051]$ for activity scores in the PPC. The latter were characterized by an increase in the levels of activity in the short trace groups (sham short trace, 408; sham long trace, 350 ; shell short trace, 490 ; shell long trace, 373).

In summary, the finding that long trace sham control animals showed a significant level of avoidance of the black chamber (i.e., an increased preference for the nonshocked side), while short trace sham controls did not significantly change their side preference, indicates that contextual conditioning occurred preferentially in the long trace groups, as expected. The behavior of shell lesioned animals was not significantly different from that of their sham controls during the tests of CS or contextual conditioning. Core lesioned animals showed a significant level of contextual conditioning in both long and short trace groups, the short trace group showing enhanced conditioning. This enhanced contextual conditioning in the short trace core lesioned group was mirrored by a significant impairment in conditioning to the discrete CS in the same animals.

\section{DISCUSSION}

This study examined aversive Pavlovian conditioning to both discrete and contextual stimuli. All animals experienced the same number of CS $\rightarrow$ US pairings within the same context; however, the extent to which animals conditioned to either the CS or the context depended critically on the temporal contiguity between the termination of the auditory CS and the onset of the footshock US. Thus, with a 5-sec interval between CS and US, shamoperated control animals conditioned predominantly to the CS at the expense of contextual conditioning, as predicted by learning theory (see, e.g., Rescorla \& Wagner, 1972). However, with a 30 -sec interval between CS and US, the lack of close temporal contiguity led to increased conditioning to the context (which was present all the time), but reduced CS conditioning. The fact that stimuli in the environment compete for associative strength during learning is a useful adaptive mechanism to help animals determine the exact predictive relationships between environmental events and is recognized and encompassed by most theories of associative learning, though the precise mechanisms through which this occurs is a matter of debate (Mackintosh, 1975; Pearce \& Hall, 1980; Rescorla \& Wagner, 1972).

\section{The Effects of Lesions to the Nucleus Accumbens Shell}

Animals with lesions of the NAcc shell were not significantly different from their sham controls on any measure taken during the experiment. Although it is possible 
A)

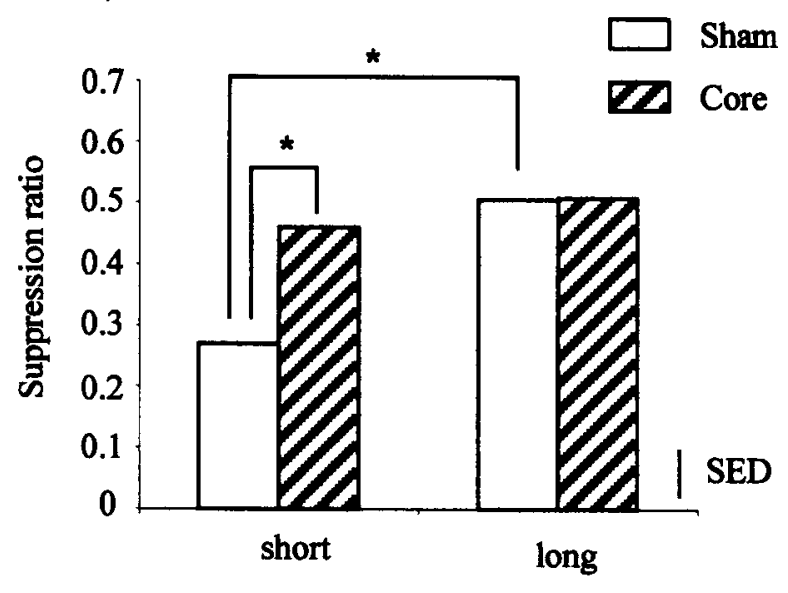

C)

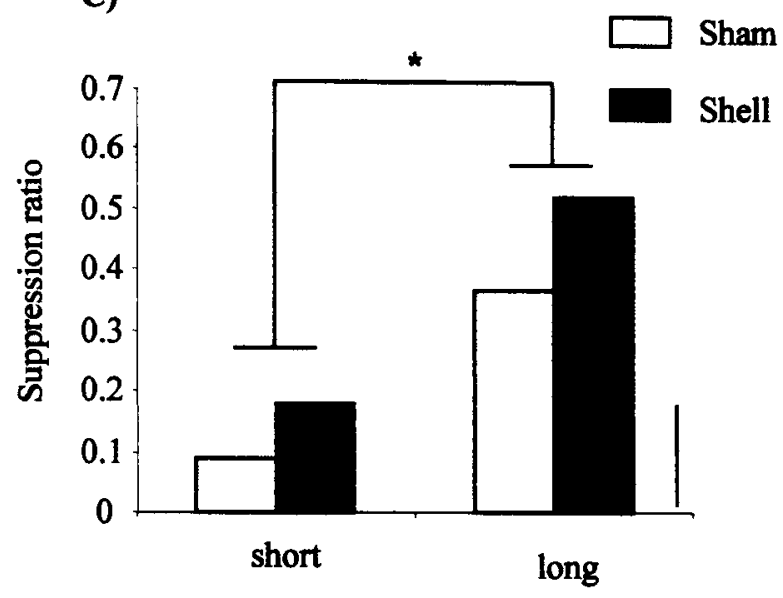

B)

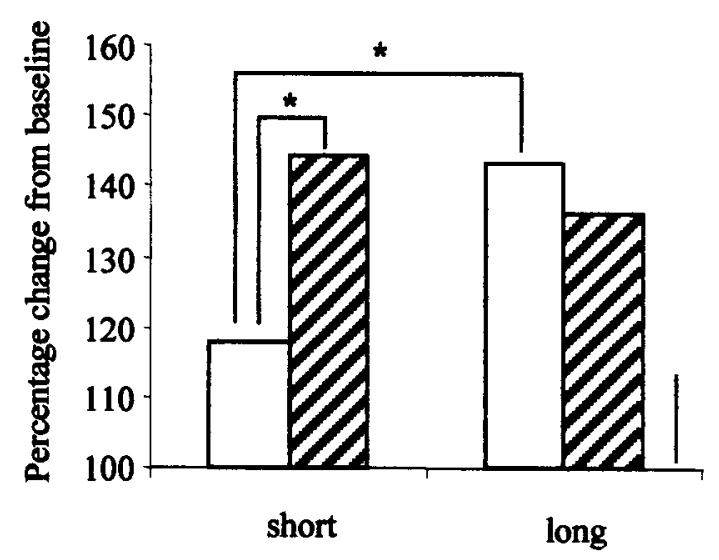

D)

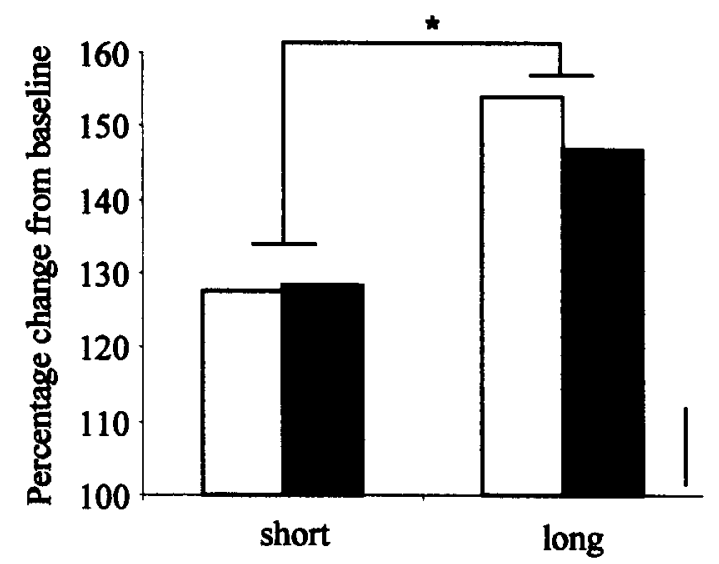

Figure 3. (A) and (C): CS conditioning as measured by lick suppression (the lower the value, the greater the level of suppression). (B) and (D): Context conditioning as measured by the percentage change in time spent in the safe area calculated pre- to postconditioning (the greater the percentage change from baseline, the greater the level of contextual conditioning). (A): NAcc core lesioned animals in the short trace group showed less suppression to the CS + , relative to short trace sham controls. (B): Long trace sham control animals showed a significantly greater preference, relative to short trace sham controls, for the safe area as measured by the percentage change from preconditioning performance. However, there was no significant difference on this measure between short and long trace NAcc core lesioned animals. Further, there was a significant difference between short trace core lesioned and short trace sham control animals in their percent change in preference. (C): There was no significant difference between NAcc shell and sham control animals in their level of suppression during the CS+ test; short trace groups showed a significantly greater level of suppression than long trace groups. (D): The long trace groups showed a significantly greater increase in the preference for the safe area in both NAce shell and sham control long trace groups.

that such lesions are too discrete to produce significant effects, it is worth noting that animals with NAcc shell lesions as described in this study do show an attenuated locomotor response to systemic injections of $d$-amphetamine and an abolished potentiation of instrumental responding for a conditioned reinforcer, by intra-NAcc $d$ amphetamine (Parkinson, Olmstead, Robbins, \& Everitt, 1999).

In this experiment, their initial responses and habituation to the apparatus and to drinking water in the lick operant chamber matched sham performance. Further, the short trace and the long trace shell lesion groups were no different from their sham lesioned controls in their level of conditioning to either the CS or to the context.

This pattern of results is perhaps surprising, for two reasons: First, the hippocampal formation sends major projections predominantly to the NAcc shell, and lesions of the hippocampus have been shown to produce severe impairments on measures of contextual conditioning (Good \& Honey, 1991; Phillips \& LeDoux, 1992; Selden 
et al., 1991). Second, research into fear and stress responses has tended to specifically implicate the NAcc shell (Beck \& Fibiger, 1995; Kalivas \& Duffy, 1995; King \& Finlay, 1997).

Although it might be predicted that lesions of the NAcc shell would result in impairments similar to those following lesions of its cortical afferent structures such as the hippocampus, recent research on functional dissociations within the hippocampal formation suggests that it is the dorsal parts of the hippocampus that are more selectively involved in spatial and contextual processing (Moser, Moser, \& Andersen, 1993; Phillips \& LeDoux, 1992). Afferent projections from the dorsal subiculum, the major output structure of the dorsal hippocampus, converge primarily onto the ventrolateral shell of the NAcc, which was explicitly not targeted by the lesions in this study. Thus the lack of effect on contextual conditioning by the NAcc shell lesions in the present study does not rule out the potential involvement of circuitry encompassing the NAcc in contextual processing; it instead shows that the mediodorsal shell is not involved in such mechanisms. Therefore, one prediction arising from the present results would be that discrete lesions of the ventrolateral shell would be more likely to produce significant impairments in contextual conditioning, although this hypothesis remains to be tested, and it may prove difficult to do so considering the topographic position of this region of the NAcc shell.

However, electrolytic lesions of the mediodorsal shell have been reported to produce impairments in contextual fear conditioning, as measured by freezing (Riedel et al., 1997). Lesioned animals were tested over 3 days (two shock pairings on the first 2 days and an extinction test on Day 3), and although impaired relative to controls, lesioned subjects still showed a significant level of contextual conditioning. These animals were not impaired on a test of discrete CS conditioning. Although this study suggests that the mediodorsal shell is involved in contextual conditioning, the lack of effect on aversive conditioning in the present study, which used excitotoxic lesions of a similar size and location, suggests that the results of Riedel et al. may have been due to damage to fibers passing through the shell region rather than to the shell itself. In fact, electrolytic mediodorsal shell lesions are very likely to damage dorsal hippocampal/subiculum projections to the ventrolateral shell, which pass through this area (Brog, Salyapongse, Deutch, \& Zahm, 1993; Groenewegen, Vermeulen-Van der Zee, Kortschot, \& Witter, 1987).

Changes in both extracellular DA and tissue levels of DA metabolites have been observed, particularly in the NAcc shell, in response to restraint stress and footshock (Deutch \& Cameron, 1992; Kalivas \& Duffy, 1995). Further, fear-associated CSs produce increases in expression of the immediate early gene c-fos in a number of brain structures, including the NAcc (Campeau et al., 1997), while a fear-associated context has also been shown to increase c-fos expression to a relatively greater degree in the NAcc shell than in the core (Beck \& Fibiger, 1995).
Although these studies implicate the NAcc shell and the mesolimbic DA system in the response to aversive stimulation, the precise functions of the shell remain unclear. They suggest that rather than being involved in aversive learning per se, the NAcc shell may instead be involved in unconditioned responses to aversive stimuli, perhaps via its selective projections to the lateral hypothalamus (Zahm \& Heimer, 1993).

\section{The Effects of Lesions to the Nucleus Accumbens Core}

Core lesioned animals showed an increased number of licks to the water spout during habituation in the lick operant chambers relative to their sham controls. However, this behavior declined over sessions to a level no different from that of shams (by Session 4). There were no other significant effects of the lesion on preconditioning measures of responses or habituation to the apparatus.

Animals with core lesions showed a significant impairment in aversive CS conditioning. Short trace animals that experienced $\mathrm{CS} \rightarrow$ US pairings with an interval of $5 \mathrm{sec}$ between the CS and US did not show suppression to that CS during a later test session. Sham controls trained and tested under the same conditions showed a significant level of suppression to the CS on test. Core lesioned animals that failed to condition to the CS did, however, go on to demonstrate enhanced conditioning to the context by showing an increased preference for the safe compartment of the apparatus after conditioning.

It is not clear as to whether the NAcc core therefore subserves associative learning or behavioral performance, although the two findings (described above) suggest that core lesioned animals failed to associate the CS with the US and instead associated the context with the US, supporting the view that the neural mechanisms underlying CS and contextual conditioning are to some extent distinct (Selden et al., 1991). In the Selden et al. (1991) study, BLA lesioned animals also showed a selective impairment in CS conditioning, while hippocampal lesioned animals showed a selective impairment in contextual conditioning. Since the BLA provides major projections to the core subregion of the NAcc, it may be that these two structures function together in Pavlovian fear conditioning.

Such reciprocity between CS and contextual conditioning in this experiment has also been observed following dorsal noradrenergic bundle lesions (Selden, Robbins, \& Everitt, 1990) and has been attributed to an overshadowing effect (of the context over discrete CSs) or the broadening of an animal's attentional span (see also Robbins \& Everitt, 1995). Thus the NAcc may similarly be involved in attentional mechanisms perhaps relating to stimulus salience or associability (Reading, Dunnett, \& Robbins, 1991).

The results following NAcc core lesions may instead suggest that the NAcc integrates information from distinct learning systems and "gain amplifies" prepotent behavioral responses in a given situation. Thus, whereas lesions to limbic afferents that subserve particular forms of as- 
sociative learning might disrupt specific associative processes, lesions to the NAcc may affect the way in which competing responses gain access to behavioral expression. Alternatively, the increase in contextual conditioning seen after NAcc core lesions (in the short trace group) may instead reflect competition for associative learning between environmental cues (Dickinson, 1980). Thus if the NAcc were involved in discrete CS $\rightarrow$ US processing, damage to such a system would allow relative domination of contextual cues for association. Manipulations of temporal contiguity and probability of reinforcement offer behavioral means of demonstrating the existence of such competitive associative learning processes (Dweck \& Wagner, 1970; Rescorla, 1968).

In apparent contrast to the results reported here, Westbrook, Good, and Kiernan (1997) reported that intraNAcc infusions of morphine disrupted contextual fear conditioning but did not disrupt discrete CS conditioning. However, it is difficult to relate directly the effects of intra-NAcc infusions of morphine to those of lesions of the NAcc itself. Infusions of morphine probably diffuse throughout a large area of the NAcc, and thus the significant impairments in contextual conditioning could be attributable to influences on the target fields of afferent projections from the dorsal subiculum (see also Westbrook et al., 1997). The pattern of opiate receptor binding within the NAcc is relatively heterogeneous, and in fact opiate receptors are predominantly found within the shell subregion (both the medial and the ventrolateral aspects, the latter receiving dorsal subiculum projections; Jongen-Relo, Groenewegen, \& Voorn, 1993).

\section{Implications for Cortico-Striatal Function}

The results of this experiment are consistent with a functional connection between the BLA and the NAcc in stimulus-reinforcer learning. NAcc core lesions produced qualitatively similar effects to those seen after BLA lesions, on the same task (Selden et al., 1991), although it should be noted that results of studies of the role of the amygdala in other forms of aversive learning have been equivocal (see, e.g., Killcross et al., 1997a, 1997b; Nader \& LeDoux, 1997). Lesions to the NAcc also produce impairments on appetitive conditioning tasks (Balleine \& Killcross, 1994; Everitt et al., 1991), as do lesions of the BLA (Everitt et al., 1991; Holland, 1997). Electrophysiological studies of the interaction between the NAcc and its major sources of afferents suggest that hippocampal and amygdala projections may "gate" subsequent afferent stimulation in qualitatively different ways (Blaha, Floresco, Phillips, \& Yang, 1997; Mulder, Hodenpijl, \& Lopes da Silva, 1998; ), which has been interpreted as evidence that the hippocampus provides general contextual control over behavior while the amygdala provides "event-related gating" enabling a rapid change in response strategies to biologically relevant events (Grace \& Moore, 1998).

In this study, excitotoxic lesions of the NAcc failed to produce any impairments in contextual conditioning. In fact, core lesions appeared to enhance such conditioning under specific experimental conditions (i.e., during short trace conditioning). It remains to be tested whether the dorsal subiculum, which projects to the NAcc, is the limbic afferent structure responsible for contextual conditioning. The ventral striatal target area for these afferents was not lesioned in the present study. The fact that this region was spared after NAcc core lesions may also offer an explanation as to why enhanced contextual conditioning was observed in these animals. Thus, if the NAcc mediates a form of response competition, then a disruption in the processing of one form of environmental stimulus would allow other stimuli to gain access to accumbensdependent processes. Lesions and manipulations of the NAcc have previously been shown to produce deficits in both spatial and contextual processing (Annett, McGregor, \& Robbins, 1989; Maldonado-Irizarry \& Kelley, 1995; Westbrook et al., 1997), and it is therefore important to localize the subregion of the NAcc that mediates such contextual processing.

The present study provides evidence for a role of the NAcc in aversive conditioning that is consistent with in vivo neurochemical and electrophysiological studies of the NAcc. For example, Campeau et al. (1997) found that the presentation of a CS previously paired with footshock increased the expression of the immediate early gene cfos in the NAcc and some of its afferents (cingulate, infralimbic, and perirhinal cortices). Williams, Rolls, Leonard, and Stern (1993) observed neurons in the monkey NAcc that fired in response to the presentation of aversive stimuli. Finally, extracellular levels of DA have been shown to be closely correlated with the ability of a CS to elicit a conditioned response (Wilkinson et al., 1998; Young et al., 1998). Wilkinson et al. observed a dissociation between mesocortical and mesolimbic DA release. Since increases in extracellular DA in the medial prefrontal cortex appeared to be related to the novelty of environmental stimuli (see also Burns, Annett, Kelley, Everitt, \& Robbins, 1996; Feenstra, Botterblom, \& Vanuum, 1995), DA release within the NAcc core region matched the extent to which animals produced a conditioned response (freezing).

Young et al. (1998; Young et al., 1993) demonstrated that NAcc DA release was related not only to biologically significant appetitive and aversive events but also more generally to stimulus-stimulus associations. Consequently, pairing a tone with light led to an increase in extracellular DA in the NAcc, while pairing tone and footshock produced larger increases in NAcc DA than footshock alone. These authors argued that mesolimbic DA is sensitive to associative contingencies regardless of the affective nature of the environmental event, a view consonant with the present results.

Thus, the results of the present experiment and recent in vivo neurochemical and electrophysiological studies suggest that the NAcc and the mesolimbic DA system are not simply a substrate for mediating reward (see Wise \& 
Rompre, 1989), but may play a more general role in both appetitive and aversive associative learning (see also Salamone, 1994).

\section{REFERENCES}

Alexander, G. E., Delong, M. R., \& Strick, P. L. (1986). Parallel organization of functionally segregated circuits linking basal ganglia and cortex. Annual Review of Neuroscience, 9, 357-381.

ANNetT, L. E., McGregor, A., \& Robins, T. W. (1989). The effects of ibotenic acid lesions of the nucleus accumbens on spatial-learning and extinction in the rat. Behavioural Brain Research, 31, 231-242.

Balleine, B., \& Killcross, S. (1994). Effects of ibotenic acid lesions of the nucleus accumbens on instrumental action. Behavioural Brain Research, 65, 181-193.

Beck, C. H. M., \& Fibiger, H. C. (1995). Conditioned fear-induced changes in behavior and in the expression of the immediate-early gene c-fos-With and without diazepam pretreatment. Journal of Neuroscience, 15(1, Pt. 2), 709-720.

Blaha, C. D., Floresco, S. B., Phillips, A. G., \& Yang, C. R. (1997). Gating of hippocampal and amygdala inputs to the nucleus accumbens by dopamine: A combined in vivo extracellular electrophysiological and electrochemical recording study. Society for Neuroscience Abstracts, 23, 505.6.

Brog, J. S., Salyapongse, A., Deutch, A. Y., \& Zahm, D. S. (1993). The patterns of afferent innervation of the core and shell in the accumbens part of the rat ventral striatum-Immunohistochemical detection of retrogradely transported fluorogold. Journal of Comparative Neurology, 338, 255-278.

Buchanan, S. L., \& Powell, D. A. (1982). Cingulate damage attenuates conditioned bradycardia. Neuroscience Letters, 29, 261-268.

Burns, L. H., Annett, L., Kelley, A. E., Everitt, B. J., \& Robbins, T. W. (1996). Effects of lesions to amygdala, ventral subiculum, medial prefrontal cortex, and nucleus-accumbens on the reaction to novelty-Implication for limbic-striatal interactions. Behavioral Neuroscience, 110, 60-73.

Cador, M., Robrins, T. W., \& Everitt, B. J. (1989). Involvement of the amygdala in stimulus reward associations-Interaction with the ventral striatum. Neuroscience, 30, 77-86.

Campeau, S., Falls, W. A., Cullinan, W. E., Helmreich, D. L., DAVIS, M., \& WATSON, S. J. (1997). Elicitation and reduction of fear: Behavioural and neuroendocrine indices and brain induction of the immediate-early gene c-fos. Neuroscience, 78, 1087-1104.

Deutch, A. Y., \& CAMERon, D. S. (1992). Pharmacological characterization of dopamine systems in the nucleus-accumbens core and shell. Neuroscience, 46, 49-56.

Devinsky, O., Morrell, M. J., \& Vogt, B. A. (1995). Contributions of anterior cingulate cortex to behavior. Brain, 118(Pt. 1), 279-306.

Di Chiara, G. (1998). A motivational learning hypothesis of the role of mesolimbic dopamine in compulsive drug use. Journal of Psychopharmacology, 12, 54-67.

Dickinson, A. (1980). Contemporary animal learning theory. Cambridge: Cambridge University Press.

DWECK, C. S., \& WAGNER, A. R. (1970). Situational cues and correlation between CS and US as determinants of the conditioned emotional response. Psychonomic Science, 18, 145-147.

Everitt, B. J., Morris, K. A., O'Brien, A., \& Robbins, T. W. (1991). The basolateral amygdala ventral striatal system and conditioned place preference-Further evidence of limbic striatal interactions underlying reward-related processes. Neumscience, 42, 1-18.

Feenstra, M. G. P., Botterblom, M. H. A., \& Vanuum, J. F. M. (1995). Novelty-induced increase in dopamine release in the rat prefrontal cortex in-vivo-Inhibition by diazepam. Neuroscience Letters, 189, 81-84

Good, M., \& Honey, R. C. (1991). Conditioning and contextual retrieval in hippocampal rats. Behavioral Neuroscience, 105, 499-509.

Grace, A. A., \& MOORE, H. (1998). Regulation of information flow in the nucleus accumbens: A model for the pathophysiology of schizo- phrenia. In M. F. Lenzenweger \& R. H. Dworkin (Eds.), The pathogenesis of schizophrenia: An experimental psychopathology perspective (pp. 123-157). Washington, DC: American Psychological Association.

Groenewegen, H. J., Vermeulen-Van der Zee, E., Kortschot, A. T., \& WITTER, M. P. (1987). Organization of the projections from the subiculum to the ventral striatum in the rat-A study using anterograde transport of phaseolus-vulgaris leucoagglutinin. Neuroscience, 23, 103-120.

HollaND, P. C. (1997). Brain mechanisms for changes in processing of conditioned stimuli in Pavlovian conditioning: Implications for behavior theory. Animal Learning \& Behavior, 25, 373-399.

imperato, A., Angelucci, L., Casolini, P., Zocchi, A., \& PuglisialLEGRA, S. (1992). Repeated stressful experiences differently affect limbic dopamine release during and following stress. Brain Research, 577, 194-199.

Jongen-Relo, A. L., Groenewegen, H. J., \& Voorn, P. (1993). Evidence for a multicompartmental histochemical organization of the nucleus-accumbens in the rat. Journal of Comparative Neurology, 337, 267-276.

Kalivas, P. W., \& DUFFY, P. (1995). Selective activation of dopamine transmission in the shell of the nucleus-accumbens by stress. Brain Research, 675, 325-328.

Kalivas, P. W., \& DUFFY, P. (1997). Dopamine regulation of extracellular glutamate in the nucleus accumbens. Brain Research, 761, 173177.

Killcross, A. S., Robiins, T. W., \& EveritT, B. J. (1997a). Different types of fear-conditioned behaviour mediated by separate nuclei within amygdala. Nature, 388, 377-380.

Killcross, A. S., Robisins, T. W., \& Everitt, B. J. (1997b). Is it time to invoke multiple fear learning systems in the amygdala? Trends in Cognitive Sciences, 1, 244-246.

KIM, J. J., \& FANSELOW, M. S. (1992). Modality-specific retrogradeamnesia of fear. Science, 256, 675-677.

KING, D., \& Finlay, J. M. (1997). Loss of dopamine terminals in the medial prefrontal cortex increased the ratio of DOPAC to DA in tissue of the nucleus accumbens shell: Role of stress. Brain Research, 767, 192-200.

LeDoux, J. E., Cicchetti, P., Xagoraris, A., \& Romanski, L. M. (1990). The lateral amygdaloid nucleus-sensory interface of the amygdala in fear conditioning. Journal of Neuroscience, 10, 1062 1069.

Mackintosh, N. J. (1975). A theory of attention: Variation in the associability of stimuli with reinforcement. Psychological Review, 82 , 276-298.

Maldonado-Irizarry, C. S., \& Kelley, A. E. (1995). Excitatory amino-acid receptors within nucleus-accumbens subregions differentially mediate spatial-learning in the rat. Behavioural Pharmacology, 6, 527-539.

Maren, S., \& Fanselow, M. S. (1996). The amygdala and fear conditioning: Has the nut been cracked? Neuron, 16, 237-240.

Mark, G. P., Blander, D. S., \& Hoebel, B. G. (1991). A conditionedstimulus decreases extracellular dopamine in the nucleus-accumbens after the development of a learned taste-aversion. Brain Research, 551, 308-310.

Marlin, N. A. (1981). Contextual associations in trace conditioning Animal Learning \& Behavior, 9, 519-523.

McCullough, L. D., Sokolowski, J. D., \& Salamone, J. D. (1993). A neurochemical and behavioral investigation of the involvement of nucleus-accumbens dopamine in instrumental avoidance. Neuroscience, 52, 919-925.

Mirenowicz, J., \& Schultz, W. (1996). Preferential activation of midbrain dopamine neurons by appetitive rather than aversive stimuli Nature, 379, 449-451.

Moser, E., Moser, M. B., \& ANdersen, P. (1993). Spatial-learning impairment parallels the magnitude of dorsal hippocampal-lesions, but is hardly present following ventral lesions. Journal of Neuroscience, 13, 3916-3925.

Mulder, A. B., HodenpiJl, M. G., \& Lopes da Silva, F. H. (1998), 
Electrophysiology of the hippocampal and amygdaloid projections to the nucleus accumbens of the rat: Convergence, segregation, and interaction of inputs. Journal of Neuroscience, 18, 5095-5102.

NADER, K., \& LeDouX, J. E. (1997). Is it time to invoke multiple fear learning systems in the amygdala. Trends in Cognitive Sciences, 1, 241-244.

ODLING-SMEE, F. J. (1975a). Background stimuli and the inter-stimulus interval during Pavlovian conditioning. Quarterly Journal of Experimental Psychology, 27, 387-392.

ODLING-SMEE, F. J. (1975b). The role of background stimuli during Pavlovian conditioning. Quarterly Journal of Experimental Psychology, 27, 201-209.

ODLING-SMEE, F. J. (1978). The overshadowing of background stimuli by an informative CS in aversive Pavlovian conditioning with rats. Animal Learning \& Behavior, 6, 43-51.

Parkinson, J. A., Olmstead, M. C., Robbins, T. W., \& Everitt, B. J. (1999). Dissociation in effects of lesions of the nucleus accumbens core and shell in appetitive Pavlovian approach behavior and the potentiation of conditioned reinforcement and locomotor activity by $d$ amphetamine. Journal of Neuroscience, 19, 2401-2411.

PAXINOS, G., \& WATSON, C. (1998). The rat brain in stereotaxic coordinates. San Diego: Academic Press.

Pearce, J. M., \& Hall, G. (1980). A model for Pavlovian learning: Variations in the effectiveness of conditioned but not of unconditioned stimuli. Psychological Review, 87, 532-552.

Pennartz, C. M. A., Dasilva, F. H. L., \& Groenewegen, H. J. (1994). The nucleus-accumbens as a complex of functionally distinct neuronal ensembles-an integration of behavioral, electrophysiological and anatomical data. Progress in Neurobiology, 42, 719.

Phillips, R. G., \& LeDoux, J. E. (1992). Differential contribution of amygdala and hippocampus to cued and contextual fear conditioning. Behavioral Neuroscience, 106, 274-285.

Powell, D. A., Watson, K., \& Maxwell, B. (1994). Involvement of subdivisions of the medial prefrontal cortex in learned cardiac adjustments in rabbits. Behavioral Neuroscience, 108, 294-307.

ReAding, P. J., Dunnetr, S. B., \& Robbins, T. W. (1991). Dissociable roles of the ventral, medial and lateral striatum on the acquisition and performance of a complex visual stimulus-response habit. Behavioural Brain Research, 45, 147-161.

RESCORLA, R. A. (1968). Probability of shock in the presence and absence of CS in fear conditioning. Journal of Comparative \& Physiological Psychology, 66, 1-5.

REsCorla, R. A., \& WAGNeR, A. R. (1972). A theory of Pavlovian conditioning: Variations in the effectiveness of reinforcement and nonreinforcement. In A. H. Black \& W. F. Prokasy (Eds.), Classical conditioning II: Current research and theory (pp. 64-99). New York: Appleton-Century-Crofts.

Riedel, G., Harrington, N. R., Hall, G., \& MacPhail, E. M. (1997). Nucleus accumbens lesions impair context, but not cue, conditioning in rats. NeuroReport, 8, 2477-2481.

Robbins, T. W., \& EveritT, B. J. (1995). Arousal systems and attention. In M. Gazzaniga (Ed.), The cognitive neurosciences (pp. 703-725). Cambridge, MA: MIT Press.

SalAmone, J. D. (1994). The involvement of nucleus-accumbens dopamine in appetitive and aversive motivation. Behavioural Brain Research, 61, 117-133.
Sananes, C. B., \& Davis, M. (1992). $N$-methyl- $D$-aspartate lesions of the lateral and basolateral nuclei of the amygdala block fear-potentiated startle and shock sensitization of startle. Behavioral Neuroscience, 106, 72-80.

SChWARTING, R., \& CAREY, R. J. (1985). Deficits in inhibitory avoidance after neurotoxic lesions of the ventral striatum are neurochemically and behaviorally selective. Behavioural Brain Research, 18, 279-283.

Selden, N. R. W., Everitt, B. J., JarRard, L. E., \& Robbins, T. W. (1991). Complementary roles for the amygdala and hippocampus in aversive conditioning to explicit and contextual cues. Neuroscience, $42,335-350$

Selden, N. R. W., Robiins, T. W., \& Everitt, B. J. (1990). Enhanced behavioral conditioning to context and impaired behavioral and neuroendocrine responses to conditioned-stimuli following ceruleocortical noradrenergic lesions-support for an attentional hypothesis of central noradrenergic function. Journal of Neuroscience, 10, 531-539.

Thierry, A. M., Tassin, J. P., BlanC, G., \& Glowinski, J. (1976). Selective activation of mesocortical dopaminergic system by stress. $\mathrm{Na}$ ture, 263, 242-244

Westbrook, R. F., Good, A. J., \& Kiernan, M. J. (1997). Microinjection of morphine into the nucleus accumbens impairs contextual learning in rats. Behavioral Neuroscience, 111, 996-1013.

Wilkinson, L. S., Humby, T., Killcross, A. S., Torres, E. M. EveritT, B. J., \& RoBbins, T. W. (1998). Dissociations in dopamine release in medial prefrontal cortex and ventral striatum during the acquisition and extinction of classical aversive conditioning in the rat. European Journal of Neuroscience, 10, 1019-1026.

Williams, G. V., Rolls, E. T., Leonard, C. M., \& Stern, C. (1993) Neuronal responses in the ventral striatum of the behaving macaque. Behavioural Brain Research, 55, 243-252.

WISE, R. A., \& BozArTh, M. A. (1987). A psychomotor stimulant theory of addiction. Psychological Review, 94, 469-492.

WISE, R. A., \& RoMPRE, P. P. (1989). Brain dopamine and reward. $A n-$ nual Review of Psychology, 40, 191-225.

Wright, C. I., Beiser, A. V. J., \& Groenewegen, H. J. (1996). Basal amygdaloid complex afferents to the rat nucleus-accumbens are compartmentally organized. Journal of Neuroscience, 16, 1877-1893.

Young, A. M. J., Ahier, R. G., Upton, R. L., Joseph, M. H., \& GraY, J. A. (1998). Increased extracellular dopamine in the nucleus accumbens of the rat during associative learning of neutral stimuli. Neuroscience, 83, 1175-1183.

YounG, A. M. J., JosEPH, M. H., \& GRAY, J. A. (1993). Latent inhibition of conditioned dopamine release in rat nucleus-accumbens. Neuroscience, 54, 5-9.

ZAHM, D. S., \& BroG, J. S. (1992). On the significance of subterritories in the accumbens part of the rat ventral striatum. Neuroscience, $\mathbf{5 0}$, 751-767.

ZAHM, D. S., \& HEIMER, L. (1993). Specificity in the efferent projections of the nucleus-accumbens in the rat-comparison of the rostral pole projection patterns with those of the core and shell. Journal of Comparative Neurology, 327, 220-232.

(Manuscript received July 14, 1998; revision accepted for publication December 21,1998 .) 